\title{
CORRELATES OF PROBLEMATIC GAMING - IS THERE SUPPORT FOR PRONENESS TO RISKY BEHAVIOUR?
}

\author{
Daniela Šincek, Jasmina Tomašić Humer \& Ivana Duvnjak \\ Faculty of Humanities and Social Sciences Osijek, J. J. Strossmayer University of Osijek, Osijek, Croatia
}

received: 7.12.2016;

revised: 24.2.2017;

accepted: 15.3.2017

\section{SUMMARY}

Background: This paper explores problematic Internet gaming in the context of other forms of risky behaviour. The basic premise is that children and adolescents at risk will display different types of risky behaviour in various settings.

Subjects and methods: Children and adolescents $(N=1150)$ were surveyed about (cyber)violence, problematic gaming (habits, motives and symptoms), self-disclosure via Facebook and self-esteem.

Results: Regular gamers were more violent both face-to-face and via the Internet, and were more prone to problematic gaming than occasional gamers. Those who played games for more than five hours per day (9\% of respondents) were classified as potentially problematic gamers. They experienced and committed more violence both face-to-face and via the Internet, were more involved in self-disclosure and had more problematic gaming symptoms than those who played for less than five hours a day, but these groups did not differ in self-esteem. Participants could choose from a list of eight different motives for their gaming; those motivated by peer communication, a sense of control, relaxation, conformism, self-efficacy and to distract from problems reported more symptoms of problematic gaming than those not motivated by these factors. Gender, age, self-esteem, self-disclosure and committing violence contributed to explaining the variance in problematic gaming, accounting for about $26 \%$ of its variance. Boys, lower self-esteem, more self-disclosure and committing both types of violence more regularly were connected with reporting more symptoms of problematic gaming. The results will be discussed in the context of a general proneness to risky behaviour.

Conclusion: Committing violence against peers (both traditional and cyber) predicts significantly problematic gaming. This supports the premise that children and adolescents at risk are prone to exhibiting different forms of risky behaviour in different settings.

Key words: problematic gaming - cyber violence - self-disclosure - risky behaviour

$* * * * *$

\section{INTRODUCTION}

The Internet offers the possibility of playing various games, from browser games, first person shooter, simulation games and massively multiplayer online roleplaying games and other hybrid forms (Kuss \& Griffiths 2012). One of the most popular online activities for children is Internet gaming and includes real time interaction most often in massively multiplayer online role-playing games (MMORPGs).

The rapid growth of Internet gaming has drawn public and scientific attention to both its positive and negative consequences. In their review of positive outcomes of gaming, Adachi and Willoughby (2012) stressed the importance of having fun while playing, and Granic et al. (2014) discussed the emotional, social and motivational benefits of gaming, like keeping the gamers in a "zone of proximal development" and the optimal balancing of frustration and accomplishment in tasks by using immediate and concrete feedback, thus resulting in more persistence in both gaming and some real-world tasks. Expecting to have fun or to experience positive emotions is often a motivation for children to engage in gaming, and games have the potential to provide a safe playground for acquiring strategies to cope with stress and learning to regulate emotions.
Computer games are becoming increasingly popular and children today spend more time playing than before (Colwell \& Payne 2000). However, alongside the positive effects mentioned above, there may be negative psychosocial consequences like low self-esteem (Colwell $\&$ Payne 2000) and aggression (Anderson \& Bushman 2001), absence of connection with others (Allison et al. 2006), aggressive behaviour and hostility (Chan \& Rabinowitz 2006), decreased academic achievement (Rehbein et al. 2010) and loneliness (Lemmens, et al. 2011a). Playing computer games can lead to a preoccupation with gaming (Allison, et al. 2006) and reduce involvement in other pursuits like school and extracurricular activities and social interaction (Griffiths 2010b).

An increase in the popularity of gaming, and the impact it has on children and young people's lives, has motivated scholars to study the characteristics of problematic gaming and gaming addiction. In the last version in the Diagnostic and Statistical Manual of Mental Disorder (American Psychiatric Association 2013) the importance of broadening the study of addictions to behavioural addictions, including gambling disorders, was recognised. Because previous versions did not recognize behavioural addictions, in this is created a reconceptualization of addictions and classification categorization, including the Internet gaming disorder. Griffiths (2005) argued that different 
types of behavioural addictions (e.g. gambling, Internet use, gaming, sex, exercise) have many similarities, and they are a part of a biopsychosocial process and share common components - salience, mood modification, tolerance, withdrawal, conflict and relapse. So, gambling disorder criteria have been adopted as the starting point for a description of gaming disorder.

\section{Problematic Internet gaming - definition and classification}

Gaming disorder can be defined as a form of excessive gaming that results in a group of cognitive and behavioural symptoms including a progressive loss of control over gaming, tolerance and symptoms of inhibition (Griffiths 2005). Problematic Internet gaming or usage, as stated by Peters and Malesky (2008, p. 481) was term "used instead of addiction in order to avoid current controversies of whether behavioral addictions exist". Although Internet gaming disorder is referred as a condition to be the subject for further research by American Psychiatric Association, still it is not recognized as an official disorder. Internet gaming disorder can be a version of Internet addiction, as a type of video game addiction or as an independent addiction (Griffiths et al. 2014). Griffiths (2010a) warns that it can be appealing to use only time spent gaming as a criterion, having in mind self-reports of 80 hours per week spent gaming, but using only this criterion will not differentiate among persons with problematic usage and persons who enthusiastically use Internet or playing, so additional criteria are needed. People addicted to video games continue to sit in front of the computer and play while neglecting other activities. They usually spend eight to ten or more hours per day, and at least thirty hours per week, participating in this activity. These behaviour is described in model of problematic online gaming (Demetrovics et al. 2012). Model propose that problematic online gaming can be described alongside six dimensions: preoccupation, overuse, immersion, social isolation, interpersonal conflicts and withdrawal. These criteria overlapped with some of the criteria specified in DSM-5 (2013) for Internet gaming disorder. Internet gaming disorder can be diagnosed if five or more of following nine criteria are met: a) preoccupation with Internet games, b) withdrawal symptoms when Internet gaming is taken away, c) the need to spend increasing amounts of time gaming, d) unsuccessful attempts to control Internet gaming, e) loss of interest in hobbies and entertainment, f) continued excessive use of Internet games despite of experienced psychosocial problems, g) deception of family members, therapists or others regarding the time spent gaming, h) use of the Internet gaming to escape or relieve a negative mood and i) loss of a significant relationship, job, or educational or career opportunity because of participation in Internet games.

Rehbein et al. (2015) found that $1.16 \%$ of German adolescents in their state-representative study were classified with IGD according to the DSM-5 criteria. Five years earlier, Rehbein et al. (2010), in a national sample, found that $3 \%$ of male and $0.3 \%$ of female adolescents satisfied the criteria for video gaming dependency, the predecessor of IGD, while it has been found that the criteria for problematic gaming is met by $4.9 \%$ of American adolescents (Desai et al. 2010). This data suggests that introducing criteria for IGD could bring some clarity to this field of research.

However, there are many controversies related to IGD. These include differentiating Internet addiction and IGD (Király et al. 2014a), the continuum of gaming problems from risk factors to real addiction (Kuss \& Griffiths 2012), differences in the risk of addiction connected with online and offline gaming (Király et al. 2014b) or different types of online games, and highlighting multiplayer online role-playing games as the most hazardous (e.g. Stetina et al. 2011). Despite this, the importance of reaching a consensus on a definition and the criteria of IGD is widely recognised by scholars (King et al. 2013, Petry et al. 2014).

Although IGD is studied separately to Internet addiction and to internalised problems, the relationship between problematic gaming and externalised problems is understudied. The connections between gambling (sports betting) and the risk of delinquent behaviour (Ricijaš et al. 2015) indicate the general risk proneness in an adolescent sample. Is this general risk proneness identifiable in other risky behaviour in cyberspace? Desai et al. (2010) concluded that gaming is normative behaviour in adolescence, but that problematic gaming is correlated with different risk factors and more related to externalised problems (e.g. fights), even in their female subsample.

\section{Correlates of problematic Internet gaming}

The risk factor of Internet use and negative effects of gaming are widely studied. The most studied phenomena of negative Internet behaviour is cyberbullying. Some studies have identified an overlap of bullying and cyberbullying behaviour (e.g. Baldry et al. 2016). The majority of Australian pre-adolescents who engage in cyberbullying also participate in face-to-face bullying and are more prone to delinquent behaviour (Shin et al. 2016).

Based on the risk factor perspective in studying aggressive and delinquent behaviour, Exelmans et al. (2015) found that playing violent games contributed significantly to delinquent behaviour, after controlling for known risk factors like peer delinquency or sensation seeking. Furthermore, based on longitudinal data, Lemmens et al. (2011b), concluded that playing violent games increased physical aggression six months later. However, Adachi and Willoughby (2011) argued that competitiveness, not violence, is the characteristic of games that results in higher levels of aggressive behaviour. According to Liau et al. (2005) gaming was one of the significant predictors of risky Internet 
behaviour (specifically meeting face-to-face someone they first encountered online). Besides gaming, giving personal information contributed significantly to risky Internet behaviour. These data give some idea that some children and youth are more prone to different types of online and offline risky behaviour.

As mentioned before, time spent gaming was one of the first criterion to differentiate gamers who are potentially problematic or addicted. Time spent gaming is positively correlated with depressive and psychosomatic symptoms (Hellström et al. 2015). Messias et al. (2011) has shown that adolescents who played video games or used the Internet for more than five hours per day reported that they experienced more sadness and suicidal thoughts. Przybylski (2014) state that children aged between ten and fifteen who spent less than an hour gaming daily had higher levels of life satisfaction and prosocial behaviour and lower levels of internalising and externalising behaviour than nonplayers, while those who played for more than three hours daily showed lower levels of life satisfaction and prosocial behaviour and higher levels of internalising and externalising behaviour than non-players. Gamers who played between one and three hours daily did not differ from non-gamers in measures of psychological adjustment.

Kuss et al. (2012) have done extensive literature review to explore nature of IGD. They indicate on problems of assessment (interviews, questionnaire with different content or simply time spent gaming) and different criteria which results in prevalence ranging from 0.3 till $30 \%$ of those who are problematic, abusive or addicted gamers. Alongside with Peters and Malesky (2008) notion, they use this terms interchangeably. They also point on some relevant correlates and consequences of problematic Internet gaming like motivation based on dysfunctional copping, fun and satisfaction, or lower level of self-esteem and decreased academic achievement. Furthermore, Lemmens et al. (2011a) indicated that social competence, self-esteem and loneliness were not only correlates but also predicted pathological gaming six months later.

Although there are study relating gaming and aggression face-to-face, research studying relation of cyberbullying and other online risky behaviour (e.g. self-disclosure in cyberspace) are lacking. Cyberbullying includes aggressive, intentional behaviour carried out by individual or groups using ICT, especially Internet and mobile phones, and victims that cannot defend itself (Smith et al. 2008). Time spent online/gaming is common correlate for both problematic gaming and cyberbullying. It should be mentioned that most games offer opportunity for communication between gamers, and having in mind aggressive and competitive nature of some MMORPGs, self-disclosing while gaming bears risks for experiencing negative evaluation, even for cyber-victimization. Having in mind functions of self-disclosure (Buhrmester \& Prager 1995 ) in childhood and adolescence (social validation, social control, self-clarification, self-expression, and relationship development), gaming can be relevant media for accomplishing some of these functions, especially social validation. In combination with low self - esteem, it can result in more time spent and more psychological involvement in gaming, even to the levels of problematic Internet gaming.

So the main aim of this research is to explore if there are, after controlling socio-demographic factors and selfesteem, significant contributions of other risky behavior (namely cyber and traditional bullying and online selfdisclosure) to problematic Internet gaming. Risk proneness will display in significant contribution of risky behavior predictors (traditional and cyberbullying and online self-disclosure), after controlling known controlling (gender, grades and self-esteem), to problematic Internet gaming.

The additional aims were to examine if those who spent more than five hours daily gaming (potentially problematic gamers) differs from those who spent less time gaming will have higher results on problematic gaming questionnaire, and in other types of risky online and offline behaviours (namely traditional and cyberbullying and online self-disclosure). Also, it was examined if these two groups differ in grades and selfesteem and motivation for gaming. We expected children and adolescents who spent more than five hours a day gaming to experience more undesirable results in terms of different behaviours, including riskier behaviour (e.g. symptoms of problematic gaming, (cyber)violence etc.). We also wanted to examine the differences in motivation for gaming. Motives will differ between those who spend more than five hours gaming and those who play less than that. Those who are motivated by a specific motive will differ, in terms of the amount of symptoms of problematic gaming they display, from those not motivated by that factor.

\section{SUBJECTS AND METHODS}

\section{Participants}

The data were collected as a part of Croatian national research focusing on children and adolescent's habits of using information and communication technologies (ICT). The total sample consisted of 7038 children and youths (non-proportional quota sampling); however, for the purpose of this paper, the subsample consists of $\mathrm{N}=1150$ children and adolescents from different elementary and high schools in both rural and urban areas. Their ages ranged from 11 to $21(\mathrm{M}=14.77$, $\mathrm{SD}=2.259$ ). In terms of gender, 533 participants were identified as male $(46.3 \%)$. All students were either in the sixth $(24.9 \%)$ or eighth $(25.6 \%)$ grades of elementary school, or in the second $(27.7 \%)$ or fourth $(21.9 \%)$ grades of high school. A total of 363 (32.1\%) participants said they never play games, so they were excluded from further analysis. 


\section{Measures}

Major sociodemographic information (age, grade, gender) and information regarding Internet use and online gaming was collected.

Online gaming questions provided information about the time spent gaming and motives for gaming. We asked respondents how often they played online games (not at all, 2-3 times per month, 2-3 times per week, every day). Answers regarding time spent playing online games on an average day were elicited using single-choice questions (1-2 hours, 3-5 hours, 5-10 hours, $>10$ hours). In order to clarify the results, and according to the findings mentioned in the introduction, the number of categories was reduced during the analyses by merging the two first and last categories into one ( $\leq 5$ and $>5$ hours).

Motives for online gaming were assessed by providing eight options. Participants answered with yes or no, depending on whether the motives were relevant for their online gaming (peer communication, selfefficacy, conformism, sense of control, relaxation, fun, availability and distractions from problems).

Problematic Online Gaming (POGQ) is a 12-item questionnaire (Pápay et al. 2013). Items were answered using a 5-point Likert scale (1=never, 5=always). The authors used this short-form version to measure six underlying dimensions of problematic gaming (i.e. preoccupation, overuse, immersion, social isolation, interpersonal conflicts and withdrawal). Principal component analysis of our data revealed one factor solution that explained $50.79 \%$ of the variance. Scores ranged from 12 to 60 , with higher scores indicating more POG. As the authors recommended (Pápay et al. 2013), a cut-off score of 32 was used to distinguish between problematic and non-problematic online gamers. The internal consistency of the 12-item POGQ was 0.91 for the present sample.

The Rosenberg Self-esteem Scale (RSE) (Rosenberg $1965)$ is a 10-item self-reporting unidimensional measure used to assess global self-esteem (e.g. "I feel that I am a person of worth, at least on an equal plane with others"). Items were answered on a 4-point scale (1=strongly disagree, $4=$ strongly agree). Scores ranged from $10-40$, with higher scores indicating higher selfesteem. Cronbach's alpha was 0.789 .

The Self-Disclosure Scale (Huling 2011) is a 21item self-reporting measure used to assess the disclosure of intimate information about the self or global selfdisclosure on the Internet. Items were answered on a 5point scale ( $1=$ never, $5=$ always). Scores ranged from 21-105, with higher scores indicating higher selfdisclosure online. Cronbach's alpha was 0.894.

The Traditional School Bullying Questionnaire (TSBQ) (Velki et al. 2011) was utilised to measure the traditional bullying experience of the participants in their school environment. Although TSBQ has subscales for traditional bullying and traditional victimisation, we used only the traditional bullying scale. This scale has 13 items to measure the covert type of traditional bullying on a 5-point Likert scale ( $1=$ never, $5=$ always $)$. Higher scores indicated more frequent traditional bullying. Cronbach's alpha was 0.82 .

The Cyberbullying Inventory (CBI) was an adaptation of Cetin et al.'s (2011) scale for the purposes of this research. General statements from the original scale were concretised (e.g. the item "gossip on the Internet" was replaced by "I gossip about others on the Internet"). Some behaviour more relevant to children and adolescents, such as "They wanted me off or I was excluded from a group on the Internet", was added into the scale. Furthermore, some items not typical for children and adolescents (e.g. "I used the Internet for fraud") and behaviours that involve forms of communication that the younger generation rarely uses (e.g. "The use of offensive language in e-mail" [children and young people rarely communicate by email, they prefer social networks]) were excluded from the scale or replaced with items that describe insulting via social media. The cyberbullying form included 21 questions, with participants asked to rate themselves on a 5 -point Likert-type scale ( $1=$ never, $5=$ =always). Higher scores indicated more frequent cyberbullying. The calculated internal consistency coefficient was $\alpha=0.93$.

\section{Procedure}

The ethics committee of the Department of Psychology approved this research, and informed consent was obtained from the adolescent participants and their parents. The data were collected during the fall semester of the 2015 school year at the participants' schools, in their classrooms, during their regularly scheduled class times. The researcher distributed the surveys (which were in a paper-and-pencil format), and students completed them independently and anonymously. Since the collection was part of a larger study, different students were allocated different sets of questionnaires. The principle of random order was used to obtain one set of questionnaires. The full survey took approximately 45 minutes to complete. After completing it, the students were given a small thank-you gift (a pen, pencil or other small school supply item).

\section{Statistical analyses}

Data were analysed using the statistical package SPSS version 20.0 (SPSS Inc., Chicago, IL). The collected data is shown with descriptive statistical parameters. Reliability tests were conducted using Cronbach's alpha test, and the following methods of analysis were used in processing the results: t-test, chisquare test, Pearson's correlation and hierarchical regression analyses. 


\section{RESULTS}

Based on how often participants played games, participants were divided into occasional (playing games sometimes; $\mathrm{n}=546 ; 47.5 \%$ ) or regular (playing games every day; $n=223 ; 19.4 \%$ ) gamers. Furthermore, boys were more likely to be regular gamers than girls $\left(\chi^{2}(1)=84.69, p<0.001\right)$. Regular gamers gained higher results in problematic online gaming $(\mathrm{t}(757)=11.32$, $\mathrm{p}=0.000)$, traditional school bullying $(\mathrm{t}(767)=4.58$, $\mathrm{p}=0.000)$ and cyberbullying $(\mathrm{t}(763)=4.97, \mathrm{p}=0.000)$ than occasional gamers.

Of the regular gamers, 71 participants stated that they played for more than five hours per day, and were thus classified as potentially problematic gamers. Furthermore, boys were more likely to play games than girls $\left(\chi^{2}(3)=226.5, p<0.001\right)$, and the girls who play games spend less time playing than boys $\left(\chi^{2}(3)=79.71\right.$, $\mathrm{p}<0.001)$. Boys provided higher results in problematic online gaming $(\mathrm{t}(757)=9.90, \mathrm{p}=0.000$, Cohen's $\mathrm{d}=0.74)$, traditional school bullying $(\mathrm{t}(767)=6.09, \quad \mathrm{p}=0.000$, Cohen's $\mathrm{d}=0.46)$ and cyberbullying $(\mathrm{t}(763)=4.74$, $\mathrm{p}=0.000$, Cohen's $\mathrm{d}=0.36$ ) than girls. There were no gender differences in self-disclosure and self-esteem. It was found that elementary school students reported lower levels of traditional school bullying $(\mathrm{t}(767)=-4.66$, $\mathrm{p}=0.000$, Cohen's $\mathrm{d}=0.33)$, cyberbullying $(\mathrm{t}(763)=-5.79$, $\mathrm{p}=0.000$, Cohen's $\mathrm{d}=0.41)$ and self-disclosure $(\mathrm{t}(729)=-4.53, \mathrm{p}=0.000$, Cohen's $\mathrm{d}=0.34)$.

When the cut-off point recommended by the authors of the POG scale was used, $124(10.8 \%)$ participants were categorised as being at high risk of problematic use; however, only 22 girls $(3.56 \%$ of female participants) were above this cut-off point.

To explore if criterion of playing more or less than five hours daily results in different consequences, we divided participants into groups of potentially problematic gamers who play games for more than 5 hours per day and the non-problematic who play less than five hours daily.

Potentially problematic gamers (those who play for more than five hours per day) experienced and committed more violence both face-to-face and via the Internet (Table 1). They were also more involved in selfdisclosure, had more problematic gaming symptoms than those who played for less than five hours daily, and earned lower grades, but these groups did not differ in self-esteem at the $1 \%$ level (but the difference was significant at the 5\% level; those who played for more than five hours daily had lower self-esteem).

Table 1. Differences in the tested variables between participants who play more than or equal to/less than five hours per day

\begin{tabular}{|c|c|c|c|c|c|c|}
\hline & & $\mathrm{N}$ & $\mathrm{M}$ & SD & $\mathrm{t}$ & Cohen's d \\
\hline Problematic online gaming & $\begin{array}{l}\leq 5 \text { hours } \\
>5 \text { hours }\end{array}$ & $\begin{array}{r}664 \\
71\end{array}$ & $\begin{array}{l}22.07 \\
33.52\end{array}$ & $\begin{array}{l}7.807 \\
9.941\end{array}$ & $9.38 * *$ & 1.281 \\
\hline Traditional school bullying & $\begin{array}{l}\leq 5 \text { hours } \\
>5 \text { hours }\end{array}$ & $\begin{array}{r}669 \\
71\end{array}$ & $\begin{array}{l}17.49 \\
22.39\end{array}$ & $\begin{array}{r}4.572 \\
11.217\end{array}$ & $3.65^{* *}$ & 0.572 \\
\hline Cyberbullying & $\begin{array}{l}\leq 5 \text { hours } \\
>5 \text { hours }\end{array}$ & $\begin{array}{r}665 \\
71\end{array}$ & $\begin{array}{l}25.59 \\
36.55\end{array}$ & $\begin{array}{r}7.529 \\
19.493\end{array}$ & $4.69 * *$ & 0.482 \\
\hline Self-disclosure & $\begin{array}{l}\leq 5 \text { hours } \\
>5 \text { hours }\end{array}$ & $\begin{array}{r}635 \\
71\end{array}$ & $\begin{array}{l}33.43 \\
39.24\end{array}$ & $\begin{array}{l}10.552 \\
17.891\end{array}$ & $2.68 * *$ & 0.396 \\
\hline Self-esteem & $\begin{array}{l}\leq 5 \text { hours } \\
>5 \text { hours }\end{array}$ & $\begin{array}{r}666 \\
71\end{array}$ & $\begin{array}{l}31.13 \\
29.72\end{array}$ & $\begin{array}{l}5.304 \\
5.785\end{array}$ & $2.11^{*}$ & 0.254 \\
\hline Grades & $\begin{array}{l}\leq 5 \text { hours } \\
>5 \text { hours }\end{array}$ & $\begin{array}{r}668 \\
70 \\
\end{array}$ & $\begin{array}{l}4.07 \\
3.47 \\
\end{array}$ & $\begin{array}{l}0.765 \\
0.783 \\
\end{array}$ & $6.30 * *$ & 0.780 \\
\hline
\end{tabular}

$* \mathrm{p}<0.05 ; * * \mathrm{p}<0.01$

Table 2. Differences in gaming motivation between groups that play more than or equal to/less than five hours per day

\begin{tabular}{|c|c|c|c|c|}
\hline & Answer & $\leq 5$ hours & $>5$ hours & $\chi^{2}$ \\
\hline \multirow[t]{2}{*}{ Peer communication } & no & 460 & 40 & $4.60 *$ \\
\hline & yes & 208 & 31 & \\
\hline \multirow[t]{2}{*}{ Self-efficacy } & no & 497 & 31 & $29.73 * *$ \\
\hline & yes & 171 & 40 & \\
\hline \multirow[t]{2}{*}{ Conformism } & no & 552 & 51 & $4.99 *$ \\
\hline & yes & 116 & 20 & \\
\hline \multirow[t]{2}{*}{ Sense of control } & no & 618 & 62 & 2.35 \\
\hline & yes & 50 & 9 & \\
\hline \multirow[t]{2}{*}{ Relaxation } & no & 382 & 39 & 0.13 \\
\hline & yes & 286 & 32 & \\
\hline \multirow[t]{2}{*}{ Having fun } & no & 207 & 30 & 3.74 \\
\hline & yes & 461 & 41 & \\
\hline \multirow[t]{2}{*}{ Availability } & no & 584 & 59 & 1.06 \\
\hline & yes & 84 & 12 & \\
\hline \multirow[t]{2}{*}{ Distractions from problems } & no & 567 & 61 & 0.43 \\
\hline & yes & 100 & 10 & \\
\hline
\end{tabular}

\footnotetext{
$* \mathrm{p}<0.05 ; * * \mathrm{p}<0.01$
} 
The majority of gamers reported that they play games motivated by having fun $(\mathrm{N}=502$ or $63.8 \%$ of gamers) or as a way to relax $(\mathrm{N}=318$ or $40.4 \%)$. Only 59 gamers $(7.5 \%)$ used gaming to gain a sense of control. Based on the data in Table 2, we see that participants from both groups were motivated less than expected by peer communication $\left(\chi^{2}=4.60\right.$, $\mathrm{p}<0.05)$ and conformism $\left(\chi^{2}=4.99, \mathrm{p}<0.05\right)$, while those who play for more than five hours were motivated more than expected by conformism compared to those who play equal to/less than five hours, who are motivated by conformism less than expected. Participant who play less than five hours were motivated less than expected by self-efficacy while those who play equal to/less than five hours were equally divided in those who are motivated by selfefficacy and those who don't have this motive for gaming $\left(\chi^{2}=29.73, \mathrm{p}<0.01\right)$.

It was found that in the subsample of gamers $(\mathrm{N}=787)$, those motivated by peer communication, selfefficacy, conformism, sense of control, relaxation and distractions from problems reported more symptoms of problematic gaming than those not motivated by these factors (Table 3 ).
In the hierarchical regression analysis contributions of socio-demographic characteristics, self-esteem and three types of risky behaviour were used as a predictor of problematic gaming as another type of risk behaviour. It was done to explore if there are some indication of correlations between different risky behaviours in cyber (and traditional) context, as it is found in traditional study of risky behaviour which suggest conjunction of risky behaviour or risk proneness. In the first step of the hierarchical regression analysis, socio-demographic variables were entered, self-esteem was only new predictor added in the second step. Risk factors were entered at the end as predictors that indicate on potentially risk behaviours. Data from hierarchical regression analyses shows that, after controlling for gender, age, grades and self-esteem, traditional bullying, cyberbullying and selfdisclosure contribute to explaining the variance of problematic online gaming. This model in total explains $26 \%$ of the variance of the criterion which indicates that there are more important predictors that have a stronger effect on problematic online gaming, for example total amount spent in gaming, type of games, personality traits like neuroticism, introversion and impulsivity (Kuss \& Griffiths 2012).

Table 3. Differences in problematic online gaming considering different motives for gaming

\begin{tabular}{|c|c|c|c|c|c|c|}
\hline & Answer & $\mathrm{N}$ & M & SD & $\mathrm{t}$ & Cohen's d \\
\hline \multirow[t]{2}{*}{ Peer communication } & no & 521 & 21.51 & 8.329 & $-7.06 * *$ & 0.55 \\
\hline & yes & 239 & 26.19 & 8.682 & & \\
\hline \multirow{2}{*}{ Self-efficacy } & no & 546 & 21.29 & 7.944 & $-8.56^{* *}$ & 0.71 \\
\hline & yes & 213 & 27.36 & 9.073 & & \\
\hline \multirow[t]{2}{*}{ Conformism } & no & 625 & 22.43 & 8.702 & $-3.94 * *$ & 0.38 \\
\hline & yes & 134 & 25.66 & 8.261 & & \\
\hline \multirow[t]{2}{*}{ Sense of control } & no & 700 & 22.40 & 8.321 & $-6.73 * *$ & 0.84 \\
\hline & yes & 59 & 30.12 & 10.033 & & \\
\hline \multirow[t]{2}{*}{ Relaxation } & no & 438 & 21.38 & 8.964 & $-6.12 * *$ & 0.45 \\
\hline & yes & 321 & 25.21 & 7.836 & & \\
\hline \multirow[t]{2}{*}{ Distractions from problems } & no & 647 & 22.23 & 8.519 & $-5.85 * *$ & 0.60 \\
\hline & yes & 111 & 27.33 & 8.401 & & \\
\hline \multirow[t]{2}{*}{ Fun } & no & 243 & 23.42 & 9.542 & 0.91 & - \\
\hline & yes & 516 & 22.80 & 8.289 & & \\
\hline \multirow[t]{2}{*}{ Availability } & no & 661 & 22.76 & 8.722 & -1.93 & - \\
\hline & yes & 98 & 24.59 & 8.488 & & \\
\hline
\end{tabular}

$* \mathrm{p}<0.05 ; * * \mathrm{p}<0.01$

Table 4. Correlations coefficients between criterion and predictors $(\mathrm{N}=1150)$

\begin{tabular}{|c|c|c|c|c|c|c|c|c|}
\hline & $\begin{array}{l}\text { Problematic } \\
\text { online gaming }\end{array}$ & Gender & Age & Grades & $\begin{array}{c}\text { Self- } \\
\text { esteem }\end{array}$ & $\begin{array}{c}\text { Traditional } \\
\text { school bullying }\end{array}$ & $\begin{array}{l}\text { Cyber- } \\
\text { bullying }\end{array}$ & $\begin{array}{c}\text { Self- } \\
\text { disclosure }\end{array}$ \\
\hline Problematic online gamin & ng & $-0.253 * *$ & 0.011 & $-0.114 * *$ & $-0.185^{* *}$ & $0.326 * *$ & $0.334 * *$ & $0.252 * *$ \\
\hline Gender & & 1 & -0.012 & $0.143 * *$ & $-0.094 * *$ & $-0.215^{* *}$ & $-0.156^{* *}$ & $-0.079 * *$ \\
\hline Age & & & 1 & $-0.401 * *$ & -0.044 & $0.145^{* *}$ & $0.195 * *$ & $0.164 * *$ \\
\hline Grades & & & & 1 & $0.170 * *$ & $-0.108 * *$ & $-0.171 * *$ & $-0.144 * *$ \\
\hline Self-esteem & & & & & 1 & $-0.120 * *$ & $-0.143 * *$ & $-0.098 * *$ \\
\hline Traditional school bullyin & & & & & & 1 & $0.651 * *$ & $0.304 * *$ \\
\hline Cyberbullying & & & & & & & 1 & $0.387 * *$ \\
\hline Self-disclosure & & & & & & & & 1 \\
\hline
\end{tabular}


Table 5. Contribution of gender, age, grades, self-esteem, traditional and cyberbullying and self-disclosure in explaining variance of problematic online gaming

\begin{tabular}{|c|c|c|c|c|c|}
\hline \multirow[b]{2}{*}{ Model } & \multirow[b]{2}{*}{ Predictors } & \multicolumn{4}{|c|}{ Problematic online gaming } \\
\hline & & $\beta$ & $\mathrm{R}^{2}$ & $\Delta \mathrm{R}^{2}$ & $\mathrm{~F}$ \\
\hline \multirow[t]{3}{*}{ Step 1} & Gender & $-0.343 * *$ & $0.128 * *$ & & $34.779 * *$ \\
\hline & Age & -0.016 & & & \\
\hline & Grades & $-0.076^{*}$ & & & \\
\hline \multirow[t]{4}{*}{ Step 2} & Gender & $-0.359 * *$ & $0.166^{* *}$ & $0.037 * *$ & $35.070 * *$ \\
\hline & Age & -0.001 & & & \\
\hline & Grades & -0.038 & & & \\
\hline & Self-esteem & $-0.196 * *$ & & & \\
\hline \multirow[t]{7}{*}{ Step 3} & Gender & $-0.304 * *$ & $0.260 * *$ & $0.094 * *$ & $35.276^{* *}$ \\
\hline & Age & $-0.075^{*}$ & & & \\
\hline & Grades & -0.020 & & & \\
\hline & Self-esteem & $-0.139 * *$ & & & \\
\hline & Traditional school bullying & $0.145^{* *}$ & & & \\
\hline & Cyberbullying & $0.140 * *$ & & & \\
\hline & Self-disclosure & $0.127 * *$ & & & \\
\hline
\end{tabular}

$* \mathrm{p}<0.05 ; \quad * * \mathrm{p}<0.01 ; \quad \beta$ - beta coefficient; $\mathrm{R}^{2}$ - coefficient of determination; $\mathrm{F}-\mathrm{F}-$ value

Boys and younger participants, lower self-esteem and more bullying, both traditional and cyber, as well as more disclosing of personal information, are connected with more problematic gaming. The male gender is the most important predictor, and together with grades, it explains almost $13 \%$ of criterion variance. Aggressive behaviour and self-disclosure (as behaviours that contain a risk of negative consequences for the actor or their environment) contribute significantly and explain $9.4 \%$ of the additional variance. In the final step of the analysis, the contribution of age becomes significant (Table 4, 5).

\section{DISCUSSION}

The main goal of this study was to examine the contribution of different predictors to the severity of gaming problems and determine the relationship between problematic gaming and other risky behaviour - (cyber)violence and online self- disclosure, after controlling age, gender, grades and level of self-esteem. The other aim was te explore is there a difference among potentially problematic gamers (those who play games prof five hours or more daily) and those who play less in various variables (problematic gaming, (cyber)violence, self-disclosure etc.). Based on the results, it is clear that there are significant differences between adolescents who play for more than five hours a day and those who play less. Playing for more than five hours could indicate problematic or addictive gaming, and $9 \%$ of gamers in our sample $(6.76 \%$ of both gamers and non-gamers) reported that they play games for more than five hours daily. In Grüsser et al.'s (2007) research, there was a significant difference between gamers who were identified as pathological (4.7 hours per day) and non-pathological (2.49 hours per day) in terms of hours spent gaming. This is criterion similar to present study, but could be found in other studies, e.g. among adolescents in the UK the prevalence of gaming is two hours a day (Hellström et al. 2012). Although model of problematic gaming (Demetrovics et al. 2012) stress the importance of criteria based on indicators of psychological dysfunction, time spent gaming also indicates possibly problematic engagement in gaming (e.g. Hellström et al. 2015). Our data also indicates that playing for more than five hours per day has negative effects; those that do so self-report more symptoms of problematic gaming, bullying and cyberbullying and disclose more about their feelings and opinions on SNS than those who play less. Generally, they are more risk prone. Adolescents who spend more time online experienced some negative/unpleasant experiences; they spend an hour more gaming on average than those who did not report such unpleasant experiences (Šincek et al. 2015). There is evidence that aggressive behaviour is interrelated with excessive gaming and that it should include the type of games that players prefer (Grüsser et al. 2007).

Approximately $75 \%$ of adolescents in industrially developed countries play video games (Drummond \& Sauer 2014). Pápay et al. (2013) found that 55.6\% of their participants played an online game in the month preceding the survey. In our sample, the percentage of gamers was $68.4 \%$.

Even though gaming is a widespread activity, there is a relatively low percentage of addicted gamers. The prevalence of gaming addictions in the USA is $8.5 \%$ (Gentile 2009), which is higher than in other populations (e.g. $0.6 \%$ in Norway, Mentzoni et al. 2011; $0.5 \%$ in Germany, Schmidt et al. 2011). People addicted to gaming usually play in situations when they have experienced failure in real life. A longitudinal research study (Gentile et al. 2011) involving pupils from Singapore found that long-term gaming, weaker social skills, lower empathy levels and higher levels of impulsiveness increase the risk of gaming addiction, as measured two years later. The same research determined that depression, anxiety, social phobias and lower grades in school 
are the outcome of problematic gaming behaviour. Furthermore, longitudinal research (Rehbein \& Baier 2013) has shown that the problematic game use of tenyear-olds led to higher values on the scale of addictions five years later. In this research, $10.8 \%$ of pupils can be described as potentially problematic gamers, meaning their results exceed the cut-off point, compared to the $8.2 \%$ found by Pápay et al. (2013). In another study, $12 \%$ of participants were found to be pathological gamers (Grüsser et al. 2007).

Regarding gender, boys are at greater risk of gaming addiction (Mentzoni et al. 2011). Long-term gaming is a risk factor for gaming addiction and the nature of online games is important; the time spent playing online games is greater and has a bigger influence than playing offline games (Schmidt et al.2011). In accordance with other research, our research also showed that boys were more likely to play games than girls, spend more time playing than girls who play games and gain higher results in problematic online gaming. Rehbein et al. (2010) found that girls play games (per day) 90 minutes less than boys and that there are $39 \%$ of the boys who play games for more than 2.5 hours a day compared to $12.6 \%$ of the girls. There is a general difference in the types of games that prefer girls and boys (Subrahmanyam et al. 2001). Games that boys play are based on imagination and fantasy (most of the computer games could fit these category). On the other hand, games that girls play are more based on reality, especially family settings.

Motivation for gaming is also of interest in understanding the development of problematic gaming, as addicted gamers differ in their gaming motivations. Gaming for fun is less problematic than gaming to earn a status or as an escape from problems or the demands of others (Hellström et al. 2012). The majority of our gamers reported fun as a motive for gaming (63.8\%). The least common motive was to achieve a sense of control, as only $7.5 \%$ of gamers reported it.

Experiencing instant success in a game and selfefficacy is more important to addicted gamers (Schmidt et al. 2011), and problematic online gaming can provide them with a coping mechanism. In our research, the two groups of gamers that differed in the number of hours spent gaming (more or less than five hours) also differed in conformism ("I play because all my friends play games"). Those who spent more than five hours daily playing chose this, as a motive to play, more than those who played for less than five hours.. Peer communication and self-efficacy motivated less than expected those who play games for less than five hours, and in group of those who play more than five hours, number of players motivated by these two motives didn't differ from number of those who weren't motivated by these motive (e.g. they were similar to expected frequencies in chi square).

In addition, higher results in the POGQ were found for those adolescents that played while motivated by the possibility of communicating with peers, gaining a sense of control, relaxation or not thinking about problems (or simply because they are good at gaming). This result possibly indicates that those children use games as a way to cope, unfortunately unsuccessfully, with problems in their real life, in the same way that some youths use drugs to sedate themselves or to cope with other problems. This pattern also indicates their higher risk proneness.

Gaming addiction can have an influence on the levels of aggressiveness of the youngsters, since they are more impulsive and accept violence more easily (Rehbein \& Baier 2013). Witnessing violence in video games increases the possibility of more violent and more hostile behaviour in real life (Bilić 2010) and the appearance of aggressive thoughts (Grüsser et al. 2007). These test results are confirmed in research conducted to show a positive connection between problematic online gaming and traditional school bullying, and problematic online gaming and cyberbullying.

One of the reasons why people are reluctant to participate in face-to-face interactions is low self-esteem (Baumeister 1993). On the other hand, people seek the approval of others and seek interactions that are not face-to-face, and those include gaming. A connection was found between low self-esteem and Internet addiction, which Armstrong et al. (2000) explained as a way of escaping the feeling of worthlessness for people with low self-esteem, which could lead them to display addictive behaviour. Earlier research examined the link between the time spent playing video games and selfesteem (Colwell \& Payne 2000; Colwell \& Kato 2003). In Loton's (2007) research, low self-esteem was related to proneness to pathological computer gaming. These results were confirmed in this research, where there is a connection between self-esteem and problematic online gaming, and between self-esteem and cyberbullying.

The data from this research highlights the importance of different behaviours that have a risk of negative consequences for the actor or their environment, like bullying or cyberbullying and self-disclosure, or of problematic gaming. Almost $10 \%$ of problematic gaming variance was explained by this combination of risky behaviours, after controlling for gender, grades, age and self-esteem. This could indicate that adolescents do not limit their risk-proneness to only one setting or behaviour; instead, they will display a variety of risky behaviours. They will not be careful enough when sharing their thoughts and feelings, they will engage more often in behaviours that hurt other people both in real life and cyberspace and they will have more symptoms of problematic gaming.

One of the risk correlates of problematic gaming is earning lower grades in school (Gentile 2009). Teachers see gaming as being connected to attention disorders, and they attribute lower grades to sleep deprivation (because of gaming through the night). Additionally, if more time is spent gaming, less time is left for doing homework, studying and everyday school activities (Drummond \& Sauer 2014). Although, teachers, and even scholars are prone to view grades as consequences, 
most of the studies are correlational, and the nature of collected data doesn't allow to infer causal relationship (meaning that it is possible that lower grades precede lowering self-esteem and more gaming involvement). In our analysis, grades are significant negative predictor of problematic gaming, meaning that those who self-report more symptoms of problematic gaming tend to have lower grades. But, grades become insignificant predictor when self- esteem is entered in HRA. It could indicate that self-esteem mediate relationship of grades and problematic gaming. Those with lower self-esteem report more symptoms of problematic gaming. Contrary to results of our study, and other research that indicate negative effects of gaming on academic success (Rehbein \& Baier 2013) some studies (Thomas \& Brown 2007, Subrahmanyam et al. 2001) have shown the positive effects of gaming, such as better processing of secondary visual stimulation, better eye-hand coordination, higher reaction speeds, the development of logical and mathematical abilities and an increase in prosocial behaviour if the games played are prosocial in nature. Gaming, used wisely, can be a great educational and therapeutic tool, but overuse has a negative effect on grades, as borne out in our research.

The correlational nature of this research limits us in reaching conclusions about nature and relation of different risky behaviour, especially causality and a longitudinal design could offer more insights into the developmental pathways of the different risky behaviours. Furthermore, including some known personal (e.g. self-control, as proposed in the general theory of crime; Gottfredson \& Hirschi 1990) or parental and peer factors (like parental supervision and peer riskiness, and peer socialisation of risky behaviour), and some other types of risky behaviour (gambling, risky sexual behaviour), would be informational.

Although it has some limitations, this research provides insights into the tendency to nest the risky behaviours. Given that anyone has the potential to become addicted, it is important to develop educational interventions that would help prevent the bad influences that follow gaming addiction from an early age. In addition, identifying those at heightened risk of developing a variety of undesirable behaviours, and creating a programme for selective or indicated prevention, while taking care not to develop conditions for deviancy training (Dodge et al. 2006), should be the goal for practitioners in this area. In creating prevention programmes and therapies, respecting empirical and theoretical similarities and differences in the variety of risky behaviours is, in our opinion, the obligatory starting point.

\section{CONCLUSIONS}

The results of this study suggest that regular gamers are more violent both face-to-face and via the Internet, and more prone to problematic gaming than occasional gamers. Participants who played games for more than five hours per day (potentially problematic gamers, 9\% of the sample) experienced and committed more violence, both traditional and cyber, they were more involved in self-disclosure and had more problematic gaming symptoms than those who played less than five hours a day, but these groups did not differ in self-esteem. Gamers motivated to play games by peer communication, a sense of control, relaxation, conformism, selfefficacy and to distract from problems report more symptoms of problematic gaming than those not motivated by these factors. Boys, lower self-esteem, more self-disclosure and more instances of committing both types of violence were factors connected with reporting more symptoms of problematic gaming. This indicates that children and youths who commit more violence (both face-to-face and via the Internet) are also more prone to other forms of risky behaviour via the Internet, specifically problematic gaming. This can be viewed as an indicator of proneness to risk, thus stressing the important need for joint endeavours in both exploring and preventing these different types of behaviour. Our data indicate the need for further (longitudinal) research which will allow insight in development of problematic gaming and enable creating models or pathways of problematic gaming and gaming addiction. Alike pathways of delinquency development, it would be useful, both for science and practice, to propose and test these models which would include different risk and protective factors, not limited only on those studied in this research. Parental behaviour and their mediation strategies, personality traits like introversion, impulsivity, depression and self-control and relation to other behavioural addiction are possible relevant factor that could gain insight in nature of problematic gaming.

These results suggest the need and possibility of prevention and intervention of development of risky behaviour, especially with boys. Information about adolescents' gender (male), lower grades and lower selfesteem, but especially co-occurrence of different types of violence or other online risky behaviour should be used to make decision of including those youth in programs of selective prevention.

\section{Contribution of individual authors:}

Daniela Šincek was involved in designing of the study, manuscript preparation, literature searches and analyses, statistical analyses, interpretation of data and writing the paper.

Jasmina Tomašić Humer was involved in designing of the study, manuscript preparation, literature searches and analyses, statistical analyses, interpretation of data and writing the paper.

Ivana Duvnjak was involved in designing of the study, manuscript preparation, literature searches and analyses, statistical analyses, interpretation of data and writing the paper. 


\section{Acknowledgements:}

This research was supported by the European Union as a part of the project "Safer Internet Centre Croatia: Making the Internet a Good and Safe Place". The European Union is not responsible for any use that may be made of the information contained therein.

Conflict of interest: None to declare.

\section{References}

1. Adachi PJ \& Willoughby T: The effect of video game competition and violence on aggressive behavior: Which characteristic has the greatest influence? Psychol Viol 2011; 1:259-74.

2. Adachi PJ \& Willoughby T: Do video games promote positive youth development? J Adolesc Res 2012; 28:155-65.

3. Allison SE, von Wahlde L, Shockley $T \&$ Gabbard GO: The development of the self in the era of the Internet and roleplaying fantasy games. Am J Psychiatry 2006; 163:381-385.

4. American Psychiatric Association: Diagnostic and statistical manual of mental disorders (5th ed.). American Psychiatric Publishing, Arlington VA, 2013.

5. Anderson CA \& Bushman BJ: Effects of violent video games on aggressive behaviour, aggressive cognition, aggressive affect, physiological arousal, and prosocial behaviour: A metaanalysis of the scientific literature. Psychol Sci 2001; 12:353-59.

6. Armstrong L, Phillips JG \& Saling LL: Potential determinants of heavier Internet usage. Int J Hum Comput Stud 2000; 53:537-50.

7. Baldry AC, Farrington DP \& Sorrentino A: Cyberbullying in youth: A pattern of disruptive behaviour. Psicologia Educativa 2016; 22:19-26.

8. Baumeister RF: Understanding the inner nature of low self-esteem: Uncertain, fragile, protective and conflicted. In Baumeister RF (ed.): Self-esteem: The puzzle of low self-regard, 201-218. Plenum, 1993.

9. Bilić $V$ : The relation between media violence and aggressive peer behaviour. Educ Sci 2010; 12:263-81.

10. Buhrmester D \& Prager K: Patterns and functions of selfdisclosure during childhood and adolescence. In Rotenberg KJ (ed.): Disclosure processes in children and adolescents, 11-56. Cambridge University Press, 1995.

11. Cetin B, Yaman E \& Peker A: Cyber victim and bullying scale: A study of validity and reliability. Comput Educ 2011; 57:2261-71.

12. Chan PA \& Rabinowitz T: A cross-sectional analysis of video games and attention deficit hyperactivity disorder symptoms in adolescents. Ann Gen Psychiatry 2006; 5:16-26.

13. Colwell $J$ \& Kato M: Investigation of the relationship between social isolation, self-esteem, aggression and computer game play in Japanese adolescents. Asian J Soc Psychol 2003; 6:149-58.

14. Colwell J\& Payne J: Negative correlates of computer game play in adolescents. Br J Psychol 2000; 91:295-310.

15. Demetrovics Z, Urbán R, Nagygyörgy $K$ et al.: The development of the Problematic Online Gaming Questionnaire (POGQ). PLoS One 2012; 7:e36417.

16. Desai RA, Krishnan-Sarin S, Cavallo D \& Potenza MN: Video-gaming among high school students: Health correlates, gender differences, and problematic gaming. Pediatrics 2010; 126:1414-24.
17. Dodge KA, Dishion TJ \& Lansford JE: Deviant peer influences in programs for youth: Problems and solutions. The Guilford Press, New York/London, 2006.

18. Drummond A \& Sauer JD: Video-games do not negatively impact adolescent academic performance in science, mathematics or reading. Plos One 2014; 9:1-5.

19. Exelmans L, Custers $K \&$ Van den Bulck J: Violent video games and delinquent behavior in adolescents: $A$ risk factor perspective. Aggressive Behav 2015; 41:267-79.

20. Gentile DA: Pathological video-game use among youth ages 8 to 18: A national study. Psychol Sci 2009; 20:594-602.

21. Gentile DA, Choo H, Liau A, Sim T, Li D, Fung D et al.: Pathological video game use among youths: A two-year longitudinal study. Pediatrics 2011; 127:319-29.

22. Gottfredson MR \& Hirschi T: A general theory of crime. Stanford University Press, Stanford CA, 1990.

23. Granic I, Lobel A \& Engels RC: The benefits of playing video games. Am Psychol 2014; 69:66-78.

24. Griffiths $M: A$ 'components' model of addiction within a biopsychosocial framework. J Subst Use 2005; 10:191-97.

25. Griffiths MD: Computer game playing and social skills: A pilot study. Magazine Psychol Sci Educ Sports 2010a; 27:301-310.

26. Griffiths MD: The role of context in online gaming excess and addiction: Some case study evidence. Int J Ment Health Addiction 2010b: 8:119-125.

27. Griffiths $M D$, King DL \& Demetrovics Z: DSM-5 internet gaming disorder needs a unified approach to assessment. Neuropsychiatry 2014; 4:1-4.

28. Grüsser SM, Thalemann $R \&$ Griffiths MD: Excessive computer game playing: Evidence for addiction and aggression? CyberPsychol Behav 2007; 10:290-92.

29. Hartley P: Interpersonal communication. Taylor \& Francis/Routledge, Florence KY, US, 1993.

30. Hellström $C$, Nilsson $K W$, Leppert $J \&$ Äslund $C$ : Influences of motives to play and time spent gaming on the negative consequences of adolescent online gaming. Comput Hum Behav 2012; 28:1379-87.

31. Hellström C, Nilsson $K W$, Leppert $J \&$ Aslund C: Effects of adolescent online gaming time and motives on depressive, musculoskeletal, and psychosomatic symptoms. Ups $J$ Med Sci 2015; 120:263-75.

32. Huling BAB: Narcissism, Facebook use and self-disclosure (Thesis). Retrieved from BYU Scholars Archive (Accession No. 2475), 2011.

33. Liau AK, Khoo A \& Hwaang P: Factors influencing adolescents' engagement in risky Internet behavior. CyberPsychol Behav 2005; 8:513-20.

34. King DL, Haagsma MC, Delfabbro PH, Gradisar $M$ \& Griffiths MD: Toward a consensus definition of pathological video-gaming: A systematic review of psychometric assessment tools. Clin Psychol Rev 2013; 33:331-42.

35. Király O, Griffiths MD, Urbán R, Farkas $J$, Kökönyei $G$, Elekes $Z$ et al.: Problematic Internet use and problematic online gaming are not the same: Findings from a large nationally representative adolescent sample. Cyber Psychol Behav Soc Networking 2014a; 17:749-54.

36. Király $O$, Nagygyörgy $K$, Griffiths $M$ \& Demetrovics $Z$ : Problematic online gaming. In Rosenberg $K \&$ Feder $L$ (eds.): Behavioral Addictions: Criteria, Evidence and Treatment, 61-97. Elsevier, $2014 b$.

37. Ko HC \& Kuo FY: Can blogging enhance subjective wellbeing through self-disclosure? CyberPsychol Behav 2009; 12:75-79. 
38. Kuss DJ \& Griffiths MD: Internet gaming addiction: A systematic review of empirical research. Int $J$ Ment Health Addiction 2012; 10:278-96.

39. Kuss DJ, Louws J \& Wiers RW: Online gaming addiction? Motives predict addictive play behavior in massively multiplayer online role-playing games. Cyberpsychol Behav Soc Networking 2012; 15:480-85.

40. Lemmens JS, Valkenburg PM \& Peter J: Psychosocial causes and consequences of pathological gaming. Comput Hum Behav 2011a; 27:144-52.

41. Lemmens JS, Valkenburg PM \& Peter J: The effects of pathological gaming on aggressive behavior. J Youth Adoles 2011b; 40:38-47.

42. Loton DJ: Problem video game playing, self-esteem and social skills: An online study (Honours thesis). Retrieved from Department of Psychology, Victoria University, 2007.

43. Mentzoni RA, Brunborg GS, Molde H, Myrseth $H$, Skouverre KJM, Hetland J et al.: Problematic video game use: Estimated prevalence and associations with mental and physical health. Cyber Psychol Behav Soc Networking 2011; 14:591-96.

44. Messias E, Castro J, Saini A, Usman M \& Peeples D: Sadness, suicide, and their association with video game and Internet overuse among teens: Results from the youth risk behavior survey 2007 and 2009. Suicide and Life Threat Behav 2011; 41:307-15.

45. Pápay O, Urbán R, Griffiths MD, Nagygyörgy K, Farkas $J$, Kökönyei $G$ et al.: Psychometric properties of the Problematic Online Gaming Questionnaire Short-Form (POGQ-SF) and prevalence of problematic online gaming in a national sample of adolescents. Cyber Psychol Behav Soc Networking 2013; 16:340-48.

46. Peters CS \& Malesky Jr. LA: Problematic usage among highly-engaged players of massively multiplayer online role playing games. Cyber Psychol Behav 2008; 481-484.

47. Petry NM, Rehbein F, Gentile DA, Lemmens JS, Rumpf HJ, Mößle $T$ et al.: An international consensus for assessing Internet gaming disorder using the new DSM-5 approach. Addiction 2014; 109:1399-406.

48. Przybylski AK: Electronic gaming and psychosocial adjustment. Pediatrics 2014; 134:716-22.

49. Rehbein $F$ \& Baier D: Family-, media-, and schoolrelated risk factors of video game addiction: A 5-year longitudinal study. J Media Psychol 2013; 25:118-28.

50. Rehbein F, Kliem S, Baier D, Mößle T\& Petry NM: Prevalence of Internet gaming disorder in German adolescents: Diagnostic contribution of the nine DSM-5 criteria in a state-wide representative sample. Addiction $2015 ; 110: 842-51$.
51. Rehbein F, Psych G, Kleimann M, Mediasci G \& Mößle T: Prevalence and risk factors of video game dependency in adolescence: Results of a German nationwide survey. Cyber Psychol Behav Soc Networking 2010; 13:269-77.

52. Ricijaš N, Dodig Hundrić D \& Kranželić V: Sports betting and other risk behavior among Croatian high-school students. Croatian Rev Rehabil Res 2015; 51:41-56.

53. Rosenberg M: Society and the adolescent self-image. Princeton University Press, Princeton NJ, 1965.

54. Schacter HL, Greenberg S \& Juvonen J: Who's to blame? The effects of victim disclosure on bystander reactions to cyberbullying. Comput Hum Behav 2016; 57:115-21.

55. Schmidt J-H, Drosselmeier M, Rohde $W$ \& Fritz J: Problematische Nutzung und Abh_ngigkeit von Computerspielen (Problematic use and addiction of video games). In Fritz J, Lampert C, Schmidt J-H \&Witting T (eds.): Kompetenzen und exzessive Nutzung bei Computerspielern: Gefordert, gefçrdert, gef hrdet, 201-252. Vistas Verlag, 2011.

56. Shin HH, Braithwaite $V \&$ Ahmed E: Cyber-and face-toface bullying: Who crosses over? Soc Psychol Educ 2016; 19:537-67.

57. Smith PK, Mahdavi J, Carvalho M, Fisher S, Russell $S$ \& Tippett N: Cyberbullying: Its nature and impact in secondary school pupils. J Child Psychol Psychiatry 2008; 49:376-385.

58. Stetina BU, Kothgassner OD, Lehenbauer $M \&$ KryspinExner I: Beyond the fascination of online-games: Probing addictive behavior and depression in the world of online gaming. Comput Hum Behav 2011; 27:473-79.

59. Subrahmanyam K, Greenfield P, Kraut,R \& Gross E: The impact of computer use on children's and adolescents' development. J Appl Dev Psychol 2001; 22:7-30.

60. Šincek D, Tomašić Humer J \& Duvnjak I: Navike korištenja interneta i njihova uloga u doživljavanju neugodnih iskustva na internetu. In Oerl M (ed.): International conference EDUvision »Modern Approaches to Teaching Coming Generation«, 143-56. EDUvision, 2015.

61. Thomas D \& Brown JS: Why we need virtual worlds. University of Southern California, 2007; 1-21.

62. Veenstra S, Vandebosch $H \&$ Walrave M: Cyberbullying: Defining, understanding and intervening. In Leukfeldt ER \& Stol WPH (eds.): Cybersafety: An introduction, 217-26. Eleven International Publishing, 2012.

63. Velki T, Kuterovac Jagodić G \& Vrdoljak G: Razvoj upitnika o nasilju među školskom djecom. Neobjavljen rad, 2011.

64. Wölfling K, Thalemann $R$ \& Grüsser-Sinopoli SM: Computer game addiction: a psychopathological symptom complex in adolescence. Psychiatr Prax 2008; 35:226-232.

Correspondence:

Assist. Prof. Daniela Šincek, PhD

Faculty of Humanities and Social Sciences Osijek,

J. J. Strossmayer University of Osijek

L. Jägera 9, 31000 Osijek, Croatia

E-mail:dsincek@ffos.hr 